\title{
Evaluasi dan Penilaian Tata Kelola Teknologi INFORMASI DI UNIVERSITAS NEGERI GORONTALO
}

\author{
Vivin Apriani Cono, Rinda Iswanti Surawan, Muhammad Rifai Katili* \\ Jurusan Teknik Informatika, Fakultas Teknik \\ Universitas Negeri Gorontalo, Indonesia \\ *Penulis korespondensi, email: mrifaikatili@ung.ac.id
}

\begin{abstract}
AbSTRAK
Tata kelola Teknologi Informasi (TI) merupakan suatu struktur dan proses yang saling berhubungan, mengarahkan dan mengendalikan pencapaian tujuan organisasi melalui penyeimbangan antara risiko dan manfaat dari teknologi informasi serta prosesnya. Tujuan penelitian ini adalah untuk mengevaluasi dan menganalisis tingkat kapabilitas tata kelola TI yang berjalan di Universitas Negeri Gorontalo (UNG). Pendekatan kuantitatif dan kualitatif digunakan dalam penelitian ini. Penelitian ini melibatkan 57 orang sebagai responden berdasarkan RACI (responsible, accountable, consulted dan informed) Chart, dan wawancara berkaitan dengan proses tata kelola TI. Hasil penelitian menunjukkan bahwa tingkat kapabilitas proses tata kelola TI pada domain APO (Align, Plan, and Organize) dan BAI (Build, Acquare, and Implement) berada pada level 3 yaitu established level. Ini menunjukan bahwa proses APO dan BAI sudah diterapkan, dikelola dan dipertahankan sesuai dengan standar yang ada. Rekomendasi yang diberikan adalah pihak manajemen kampus perlu membuat suatu kebijakan dalam perencanaan pengembangan, yaitu pengetahuan dan keterampilan personel dan pengguna aplikasi TI perlu terus ditingkatkan melalui training yang terjadwal secara rutin. Selain itu, komitmen pihak manajemen UNG terhadap penggunaan TI perlu ditingkatkan agar lebih peduli terhadap pemanfaatan TI di lingkungan UNG.
\end{abstract}

Kata kunci: COBIT 5, strategi organisasi, tata kelola

\begin{abstract}
Information Technology (IT) governance is an interconnected structure and process which direct and control the achievement of organizational goals by balancing the risks and benefits of information technology and its process. The study reported in this article, therefore, sought to evaluate and analyze the level of IT system currently employed at the Universitas Negeri Gorontalo (UNG) or State University of Gorontalo. To collect data, quantitative and qualitative approaches were used, involving 57 respondents who were selected using the RACI Chart. Interviews pertaining to the IT governance process were also carried out. The results showed that the level of capability of the IT governance process in the APO and BAI domains was at level 3, namely, the established level. This shows that the $A P O$ and BAI processes have been implemented, managed and maintained in accordance with the existing standard. The study suggests that the university needs to propose a development planning policy, in which improvement on the knowledge and skills of the IT team and IT application users are facilitated through sustainable training programs. In addition, the university may need to improve its commitment on ensuring effective uses of IT in the future.
\end{abstract}

Keywords: COBIT 5, organization strategy, governance 


\section{Pendahuluan}

Saat ini, teknologi informasi (TI) telah menjadi bagian penting dalam strategi organisasi pendidikan tinggi. Hal ini tidak terlepas dari peluang dan tantangan pendidikan tinggi di era disrupsi (Oey-Gardiner, 2017). Secara konsep, reputasi perguruan tinggi ditentukan juga oleh penggunaan TI untuk menjadikan perguruan tinggi lebih kompetitif dan inovatif. Di Universitas Negeri Gorontalo (UNG), pemanfaatan TI telah masif digunakan untuk melakukan layanan akademik sesuai dengan kebutuhan yang ada. Sebagai contohnya adalah layanan melalui sistem aplikasi seperti Sistem Informasi Akademik Terpadu (SIAT), SITU, SIRBA, dan sistem aplikasi lainnya (Tim TIK UNG, 2016). Pentingnya layanan melalui sistem aplikasi untuk melakukan kegiatan operasional di UNG, menjadikannya perlu adanya evaluasi dan penilaian terhadap tata kelola TI. Hal ini penting dilakukan agar manajemen kampus dapat mengukur dan memastikan bahwa penggunaan TI adalah sesuai dengan harapan untuk mencapai tujuan dan strategi organisasi.

Tata kelola TI merupakan suatu struktur dan proses yang saling berhubungan serta mengarahkan dan mengendalikan organisasi dalam pencapaian tujuan organisasi melalui nilai tambah dan penyeimbang antara risiko dan manfaat dari teknologi informasi serta prosesnya. Sebagai implikasinya, suatu tata kelola TI yang terintegrasi dan terstruktur yang dimulai dari proses perancangan sampai dengan proses pengawasan adalah untuk memastikan bahwa TI dapat mendukung pencapaian tujuan organisasi (Amali dkk, 2014).

Menurut Van Grembergen (2004), Tata kelola TI adalah kapasitas organisasi yang dilakukan oleh dewan, manajemen eksekutif dan manajemen TI untuk mengendalikan rumusan dan implementasi strategi TI dan dengan cara ini memastikan perpaduan antara bisnis dan TI. Manakala menurut Weill \& Ross (2004), tata kelola TI adalah menentukan kerangka kerja keputusan dan akuntabilitas untuk mendorong perilaku yang diinginkan dalam penggunaan TI.

Pentingnya tata kelola TI menurut Weill \& Ross (2004) yaitu:

1. Tata kelola TI dapat meningkatkan efektivitas aktivitas manajemen dalam berbagai area.

2. Memfokuskan TI untuk mendukung strategi organisasi.

3. Tata kelola TI yang baik dapat mempertanggungjawabkan setiap keputusan yang dihasilkan untuk segala sesuatu terkait aktivitas TI.

4. TI dapat mendorong terciptanya kesempatan bisnis baru bagi organisasi.

5. Tata kelola TI yang efektif dapat menciptakan mekanisme untuk mengetahui tentang nilai dari TI.

6. Tata kelola TI dapat menciptakan proses pengambilan keputusan terkait TI dengan jelas dan transparan.

Evaluasi ITG memiliki beberapa standar yang satu diantaranya adalah menggunakan kerangka kerja COBIT 5. COBIT 5 merupakan generasi terbaru dari panduan ISACA terkait tata kelola dan manajemen TI. COBIT 5 bersifat umum dan dapat digunakan untuk semua jenis organisasi, baik kecil maupun besar. Maksud utama COBIT ialah menyediakan kebijakan yang jelas dan good practice untuk IT governance, membantu manajemen senior dalam memahami dan mengelola risiko-risiko yang berhubungan dengan IT. Kerangka kerja COBIT 5 memiliki 5 prinsip (ISACA, 2012a), yaitu:

1. Memenuhi kebutuhan pemangku kepentingan

2. Meliputi perusahaan dari ujung ke ujung

3. Menerapkan kerangka kerja terintegrasi tunggal

4. Mengaktifkan pendekatan holistik

5. Memisahkan tata kelola dari manajemen. 
Adapun penilaian tingkat kapabilitas pada COBIT 5 didasari pada ISO/IEC 15504, yaitu standar mengenai Software Engineering dan Process Assesment Model (ISACA, 2012b). Tingkat kapabilitas itu sendiri merupakan sebuah model yang menggambarkan bagaimana suatu proses inti di dalam organisasi berjalan. Selain itu, COBIT menyediakan pengukuran performance atau kinerja dari proses-proses pada area tata kelola maupun manajemen. Pada COBIT 5, dimensi kapabilitas terdiri atas 6 tingkatan/level dalam pengukuran kapabilitas proses COBIT 5 (ISACA, 2012a), seperti berikut:

1. Level 0 (Incomplete Process) proses yang belum lengkap. Proses tidak dilaksanakan atau gagal untuk mencapai tujuan prosesnya.

2. Level 1 (Performed Process) performa proses. Proses dilakukan dan mencapai tujuan prosesnya.

3. Level 2 (Managed Process) proses yang dilakukan sekarang dan diimplementasikan, dikelola, dimonitor, dan disesuaikan dan produk yang tepat dipertahankan dan juga dikendalikan.

4. Level 3 (Enablished Process) proses yang dikelola sebelumnya kini diimplementasikan menggunakan proses yang mampu mencapai prosesnya.

5. Level 4 (Predictable Process) proses yang berjalan dan ditetapkan sekarang beroperasi dalam mendefinisikan batas untuk mencapai hasil prosesnya.

6. Level 5 (Optimising Process) proses diprediksi dan dijelaskan sebelumnya terus ditingkatkan guna memenuhi tujuan bisnis yang relevan saat ini.

Model referensi proses dalam COBIT 5 memuat perbedaan yang jelas antara tata kelola dan manajemen (Fu dan Mittnight, 2015; ISACA, 2012a) (Gambar 1), yaitu:

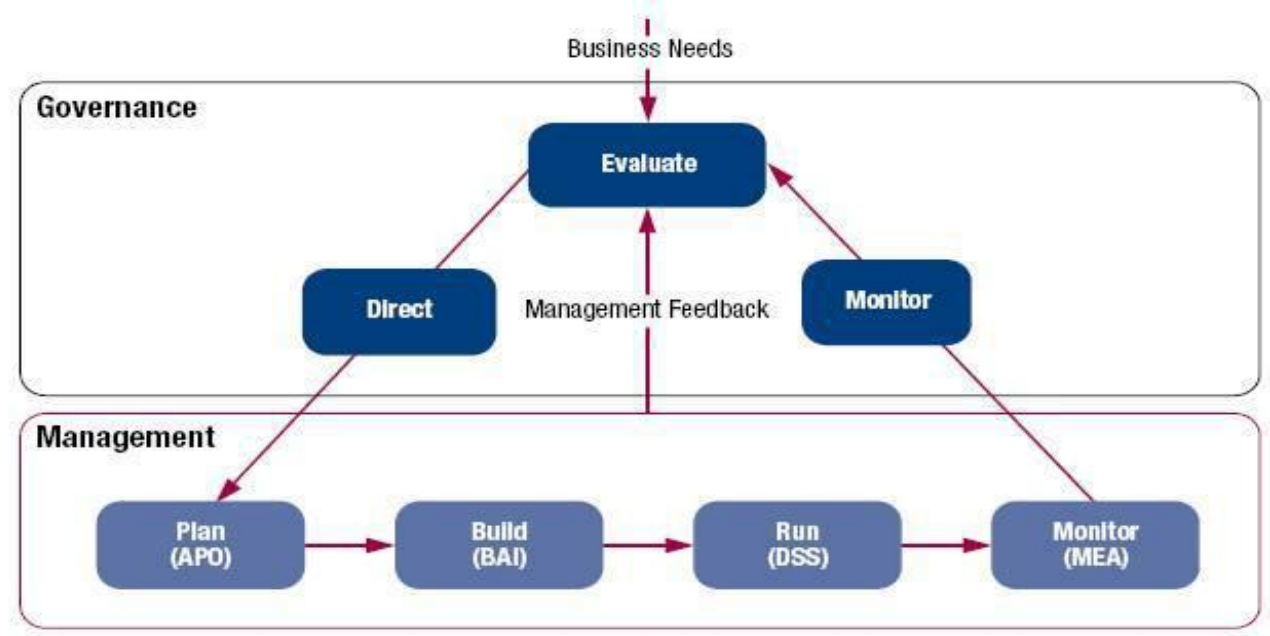

Gambar 1. Tata kelola dan manajemen pada COBIT 5 (ISACA, 2012a)

1. Tata Kelola, memuat 5 proses tata kelola, dimana ditentukan praktik-praktik dalam setiap proses Evaluate, Direct, dan Monitor (EDM).

2. Manajemen, memuat empat domain, sejajar dengan area tanggung jawab dari Plan, Build, Run, and Monitor (PBRM), dan menyediakan ruang lingkup TI yang menyeluruh dari ujung ke ujung, yaitu:

a. Align, Plan, and Organize (APO): Penyelarasan, Perencanaan, dan Pengaturan.

b. Build, Acquare, and Implement (BAI): Membangun, Memperoleh, dan Mengimplementasikan.

c. Deliver, Service, and Support (DSS): Mengirimkan, Layanan, dan Dukungan.

d. Monitor, Evaluate, and Assess (MEA): Pengawasan, Evaluasi, dan Penilaian. 
Pada penelitian ini, domain APO khususnya proses APO01, APO02 dan APO07, dan BAI khususnya proses BAI01, BAI02, dan BAI06, dijadikan sebagai fokus kajian karena dianggap sesuai dengan kondisi manajemen TI di UNG saat ini, yaitu kebutuhan untuk mengelola sumber daya manusia, dan memastikan kebutuhan perubahan yang cepat.

Domain APO terdiri atas 13 proses (ISACA, 2012a) yang menjelaskan tentang pertimbangan mengenai keputusan yang diambil. Domain ini mencakup strategi dan taktik, dan mengidentifikasi kekhawatiran cara terbaik TI agar dapat berkontribusi pada pencapaian tujuan organisasi. Realisasi visi strategis perlu direncanakan, dikomunikasikan dan dikelola untuk perspektif yang berbeda. Sebuah organisasi yang tepat, serta infrastruktur teknologi, harus dimasukkan ke dalam tempatnya. Adapun domain BAI terdiri atas 10 proses (ISACA, 2012a), merupakan satu dari domain COBIT 5 yang termasuk Management of Enterprise IT. Domain BAI berfungsi memberikan solusi yang tepat sehingga berubah menjadi layanan. Oleh karena itu, diperlukan adanya identifikasi dan implementasi yang terstruktur pada proses bisnis dalam mewujudkan strategi TI (Amali \& Katili, 2018; Surendro, 2009). Pemeliharan dan perubahan sistem yang ada juga diliputi oleh domain BAI, untuk memastikan bahwa solusi akan terus memenuhi tujuan bisnis.

Penelitian ini bertujuan untuk mengevaluasi tata kelola TI sesuai dengan framework COBIT 5 dan menilai sejauh mana tingkat kapabilitas (capability level) TI di UNG. Diharapkan dengan evaluasi dan penilaian tersebut dapat diketahui seberapa jauh keselarasan antara strategi TI dan strategi organisasi di UNG.

\section{Metode}

Penelitian ini menggunakan metode deskriptif kuantitatif-kualitatif (Creswell, 2009) dengan teknik pengumpulan data menggunakan kuesioner yang dikombinasikan dengan wawancara dan studi dokumentasi. Responden dalam penelitian ini adalah sejumlah 57 orang yang memenuhi kriteria matriks RACI (responsible, accountable, consulted dan informed) (ISACA, 2009). Penelitian dilakukan melalui tahapan seperti ditunjukkan pada Gambar 2.

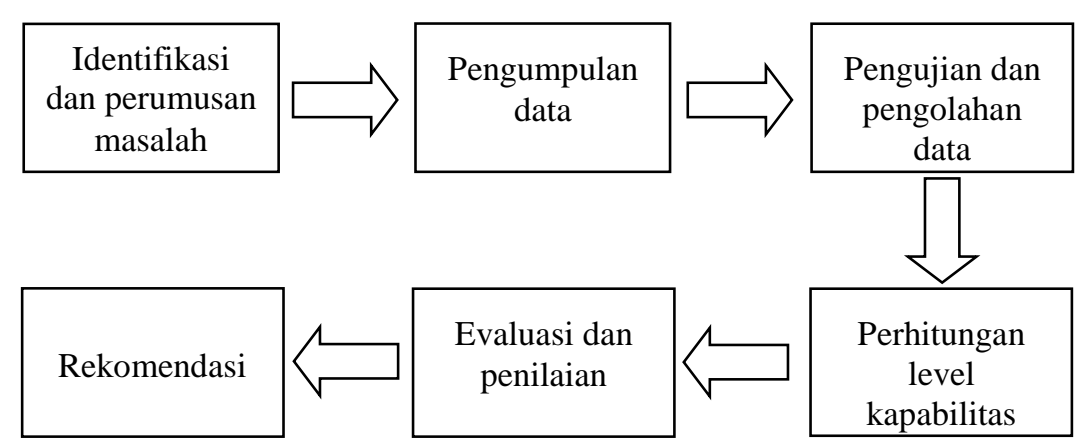

Gambar 2. Tahapan penelitian

\section{HASIL DAN DISKUSI}

\section{Deskripsi Tingkat Kapabilitas}

Analisis tingkat kapabilitas digunakan untuk mengevaluasi dan mengukur tingkat kapabilitas proses pada domain APO (Cono, 2019) dan BAI (Surawan, 2019) di UNG berdasarkan data yang diperoleh dari responden. Dalam melakukan pengukuran terhadap capability level tata kelola TI UNG, digunakan kuesioner sebagai metode pengumpulan data yang berisi nilai indeks 
dari masing-masing kriteria pada pengukuran yang dilakukan. Perhitungan dalam menentukan indeks dari setiap proses domain yang telah dikelola ditunjukkan pada Tabel 1.

Tabel 1. Hasil perhitungan tingkat kapabilitas pada domain BAI dan APO

\begin{tabular}{cc|cc}
\hline Domain & Index & Domain & Index \\
\hline BAI01 & 3.31 & APO01 & 3.56 \\
\hline BAI02 & 3.20 & APO02 & 3.37 \\
\hline BAI06 & 3.19 & APO07 & 3.51 \\
\hline Total & 9.70 & Total & 10.4 \\
\hline Index average & 3.23 & Index average & 3.47 \\
\hline
\end{tabular}

Berdasarkan data rekapitulasi di atas, hasil perhitungan tingkat kapabilitas pada proses BAI01, BAI02 dan BAI06 adalah sebagai berikut (Surawan, 2019):

1. Tingkat kapabilitas saat ini untuk proses mengelola program dan proyek (BAI01) berada pada level 3 dengan nilai kematangan 3,31.

2. Tingkat kapabilitas saat ini untuk proses mengelola definisi kebutuhan (BAI02) berada pada level 3 dengan nilai kematangan 3,20.

3. Tingkat kapabilitas saat ini untuk proses mengelola perubahan (BAI06) berada pada level 3 dengan nilai kematangan 3,19.

Sedangkan hasil tingkat kapabilitas pada proses APO01, APO02 dan APO07 memiliki kesimpulan sebagai berikut (Cono, 2019):

1. Tingkat kapabilitas saat ini untuk proses mengelola manajemen kerangka kerja TI (APO01) mengarah pada level 4 dengan nilai kematangan 3,56.

2. Tingkat kapabilitas saat ini untuk proses mengelola strategi (APO02) berada pada level 3 dengan nilai kematangan 3,37.

3. Tingkat kapabilitas saat ini untuk proses mengelola sumber daya manusia (APO07) mengarah pada level 4 dengan nilai kematangan 3,51.

\section{Analisis Kesenjangan}

Dengan adanya tingkat kematangan yang sebenarnya (as-is) dan tingkat target kematangan yang diharapkan (to-be) pada ketiga proses yang berjalan di UNG, untuk mencapai tingkat kematangan yang diharapkan, maka dibutuhkan penyesuaian agar tingkat kematangan yang diharapkan dapat terwujud. Tingkat kematangan saat ini (Current Capability) merupakan nilai rata-rata dari tingkat kematangan yang sebenarnya (as-is) pada proses BAI01, BAI02 dan BAI06, dan APO01, APO02 dan APO07. Adapun tingkat kematangan target (Expected Level) merupakan nilai dari tingkat target kematangan yang diharapkan (to-be) dan Gap merupakan kesenjangan antara Current Capability dan Expected Level.

Berikut ini adalah analisis kesenjangan dari masing-masing tingkat kematangan seperti terlihat pada Tabel 2.

1. Domain BAI (Surawan, 2019)

a. BAI01-Mengelola Program dan Proyek

Dari hasil analisis dan tingkat kapabilitas pada BAI01, diperoleh bahwa nilai capability level BAI01 berada pada level 3 yaitu Established Process dengan memiliki nilai kematangan 3 dan level target yang ingin dicapai yaitu berada pada level 4 , yaitu predictable process. Untuk mencapai level 4 predictable process, UNG harus mencapai kategori Fully Achieved pada level 3 dan gap yang dimiliki UNG pada BAI01 sekitar 0,69 . 
b. BAI02-Mengelola Definisi Kebutuhan

Dari hasil analisis dan tingkat kapabilitas pada BAI02, diperoleh bahwa nilai capability level BAI02 berada pada level 3 yaitu Established Process dengan memiliki nilai kematangan 3 dan level target yang ingin dicapai yaitu berada pada level 4, yaitu predictable process, sehingga untuk mencapai level 4 predictable process, UNG harus mencapai kategori Fully Achieved pada level 3 dan gap yang dimiliki UNG pada BAI02 sebesar 0,80 .

c. BAI06-Mengelola Perubahan

Dari hasil analisis dan tingkat kapabilitas pada BAI06, diperoleh bahwa nilai capability level BAI06 berada pada level 3 yaitu Established Process dengan memiliki nilai kematangan 3 dan level target yang ingin dicapai yaitu berada pada level 4 yaitu predictable process, sehingga untuk mencapai level 4 predictable process, UNG harus mencapai kategori Fully Achieved pada level 3 dan gap yang dimiliki UNG pada BAI06 sebesar 0,81 .

Tabel 2. Analisis gap

\begin{tabular}{llcccc}
\hline Domain & \multicolumn{1}{c}{ Prosess } & $\begin{array}{c}\text { Tingkat } \\
\text { Kapabilitas } \\
\text { Saat Ini }\end{array}$ & $\begin{array}{c}\text { Tingkat } \\
\text { Kematangan } \\
\text { Target }\end{array}$ & Gap \\
\hline BAI01 & Mengelola Program dan Proyek & 3,31 & 4 & 0,69 \\
\hline BAI02 & Mengelola Definisi Kebutuhan & 3,20 & 4 & 0,80 \\
\hline BAI06 & Mengelola Perubahan & 3,19 & 4 & 0,81 \\
\hline APO01 & Mengelola Manajemen Kerangka Kerja TI & 3.56 & 5 & 1.44 \\
\hline APO02 & Mengelola Strategi & 3.37 & 4 & 0.63 \\
\hline APO07 & Mengelola Sumber Daya Manusia & 3.51 & 5 & 1.49 \\
\hline
\end{tabular}

2. Domain APO (Cono, 2019)

a. APO01-Mengelola Manajemen Kerangka Kerja TI

Dari hasil yang didapat, proses ini berada pada level 4 (Predictable Process) dengan tingkat kematangan 3.55, yang artinya organisasi telah melakukan proses implementasi TI dalam batasan yang ditentukan untuk mencapai tujuan. Untuk level target yang ingin dicapai oleh UNG yaitu berada pada level 5 (Optimising Process), dengan nilai gap yang dimiliki UNG dalam proses ini yaitu senilai 1.45 .

b. APO02-Mengelola Strategi

Dari hasil yang didapat, proses ini berada pada level 3 (Established Process) dengan tingkat kematangan 3.38, yang artinya organisasi sudah mengimplementasikan. Proses ini UNG selalu mengupayakan kebutuhan organisasi, baik itu insfrastruktur dan juga sumber daya manusia yang mampu mendukung kinerja organisasi dalam pencapaian tujuan. Untuk level target yang ingin dicapai oleh UNG yaitu berada pada level 4 (Predictable Process), dengan nilai gap yang dimiliki UNG dalam proses ini yaitu senilai 0.62 .

c. APO07-Mengelola Sumber Daya Manusia

Dari hasil yang didapat, proses ini berada pada level 4 dengan tingkat kematangan 3.51, yang artinya organisasi telah melakukan proses implementasi TI dalam batasan yang ditentukan untuk mencapai tujuan. Dimana pada proses ini UNG sudah mengupayakan 
kemampuan sumber daya manusia untuk memenuhi tujuan orgnisasi dalam hal mengkomunikasikan peran dan tanggung jawab, rencana pengembangan dan ekspetasi kinerja yang didukung oleh staf-staf yang kompeten dan termotivasi. Untuk level target yang ingin dicapai oleh UNG yaitu berada pada level 5 (Optimising Process), dengan nilai gap yang dimiliki UNG dalam proses ini yaitu senilai 1.49 .

Dari uraian di atas, dapat disimpulkan bahwa pada domain BAI01, BAI02, dan BAI06 seluruhnya berada pada level 3 yaitu Established Process. Demikian pula halnya pada domain APO01, APO02 dan APO07 berada pada tingkat kematangan level 3 (Established Process). Hal ini dapat dikatakan bahwa proses tata kelola TI di UNG sudah dilakukan tetapi belum berjalan secara optimal, telah memiliki pola yang berulangkali dilakukan dalam melakukan manajemen aktivitas terkait dengan tata kelola teknologi informasi, namun keberadaannya belum terdefinisi secara baik dan formal sehingga masih terjadi ketidakkonsistenan.

Adapun level target yang ingin dicapai oleh UNG yaitu berada pada level 4 yaitu Predictable Process, khususnya proses pada domain BAI dan proses APO02. Tetapi pada proses APO01 dan APO07 level target yang ingin dicapai berada pada level 5 yaitu Optimising Process. Untuk memenuhi level target tersebut berarti bahwa proses yang dikelola telah dideskripsikan sebelumnya dan telah diimplementasikan menggunakan proses yang didefinisikan sehingga mampu mencapai hasil proses yang diinginkan. Dengan adanya tingkat kematangan yang sebenarnya (as-is) dan tingkat target kematangan yang diharapkan (to-be) pada proses kedua domain yang berjalan di UNG, untuk mencapai tingkat kematangan yang diharapkan dibutuhkan penyesuaian agar tingkat kematangan yang diharapkan dapat terwujud.

Representasi pemetaan tingkat kematangan pada domain BAI (Gambar 3a) dan APO (Gambar 3b) ditunjukkan pada Gambar 3.

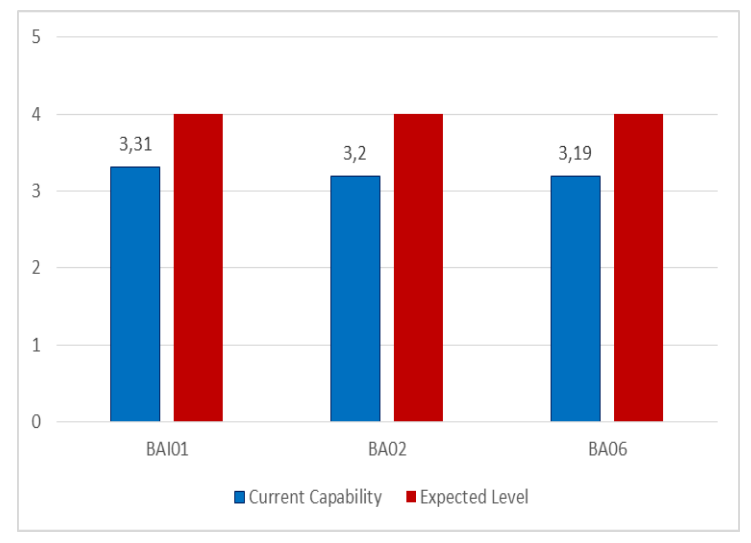

(a) BAI

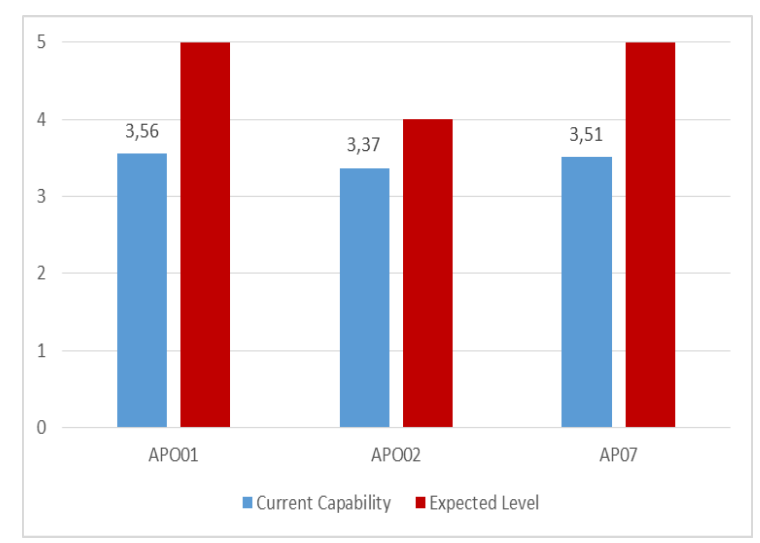

(b) APO

Gambar 3. Diagram representasi pemetaan capability level

Selain itu dari Tabel 2 dapat dijelaskan mengenai tingkat kesenjangan daripada tingkat kematangan aplikasi TI yang telah diimplementasikan. Kesenjangan terkecil berada pada proses Mengelola Strategi (APO02) pada domain APO sedangkan kesenjangan terbesar berada pada proses Mengelola Sumber Daya Manusia (APO07). Kesenjangan pada proses Mengelola Strategi menunjukkan bahwa aplikasi TI yang diimplementasikan selama ini di UNG tidak mudah beradaptasi terhadap tuntutan perubahan dan dinamika yang terjadi. Pada sisi lain, terkait dengan SDM, adalah kurangnya kemampuan pengelola TI dalam mengelola masalah yang timbul sehingga berpengaruh pada lemahnya kemampuan para pengelola TI dalam mengidentifikasi dan mengantisipasi perubahan-perubahan yang terjadi. 


\section{Rekomendasi}

Berdasarkan hasil evaluasi dan penilaian tingkat kapabilitas mengenai nilai tingkat kematangan saat ini dengan tingkat kematangan yang diharapkan (expected level), dapat disampaikan rekomendasi pada setiap proses domain, sebagai berikut (Cono, 2019; Surawan, 2019):

1. Mengelola Program dan Proyek (BAI01)

a. Perlu adanya SOP yang mengatur pengelolaan program khusus untuk penggadaan barang dalam hal fasilitas TI.

b. Membuat laporan dari masing-masing bagian kerja secara rutin terhadap kondisi pengelolaan pengelolaan proyek dalam sebuah program kepada penentu kebijakan sehingga dapat diambil kebijakan apabila terdapat kendala.

c. Membuat keputusan dengan memprioritaskan alokasi anggaran untuk perencanaan dan pengadaan program dan proyek.

d. Perlu ada SOP dalam mengelola kualitas program dan proyek.

e. Melakukan pengawasan dan pengecekan secara berkalsa terkait jalannya program dan proyek sejauh mana dapat berfungsi dan melakukan penanganan secara cepat apabila terdapat kendala.

2. Mengelola Definisi Kebutuhan (BAI02)

a. Dalam Menjalankan studi kelayakan dan merumuskan solusi alternatif, dilakukan proses menentukan dan melaksanakan studi kelayakan, panduan atau solusi kerja dasar yang jelas dan ringkas menjelaskan solusi alternatif yang akan memenuhi kebutuhan bisnis dan fungsional.

b. Dalam mengelola resiko kebutuhan perlu dibuatkan SOP tentang mendokumentasi aksi yang dilakukan untuk mengurangi resiko kebutuhan.

3. Mengelola Perubahan (BAI06)

a. Membuat SOP terkait dengan pengaturan perubahan. Semua Divisi pada UPT TIK diharapkan mampu berpedoman kepada dokumen SOP untuk setiap ada tindakan perubahan.

b. Mempunyai laporan status perubahan yang mencatat status awal perubahan dan status akhir perubahan secara tertulis.

4. Mengelola Manajemen Kerangka Kerja TI (APO01)

a. Meningkatkan pelayanan, pengelolaan dan penanganan masalah TI terhadap unit kerja baik dosen, pegawai, maupun mahasiswa agar lebih baik untuk mencapai tujuan dalam visi "Terdepan dalam Layanan TI" (Tim TIK UNG, 2016) dan menerapkan manajemen kampus berbasis ICT.

b. Membuatkan suatu media atau wadah yang dapat menampung saran dan masukan dari user untuk menilai dan meningkatkan pengelolaan TI di UNG dan mengkomunikasikannya secara luas dalam organisasi.

c. Membuat kebijakan atau SOP dalam perencanaan pengembangan TI.

5. Mengelola Strategi (APO02)

a. Memprioritaskan alokasi anggaran TI untuk program pelayanan TI dan pengadaan serta pemanfaatan perangkat maupun infrastruktur untuk pengelolaan permasalahan TI.

b. Meningkatkan pengembangan dan pemeliharaan terhadap jaringan mendukung layanan TI.

c. Meningkatkan pengembangan dan pemeliharaan serta pengamanan terhadap sistem akademik untuk mendukung layanan TI.

d. Meningkatkan keamanan sistem dan menerapkan pola pemeriksaan dan evaluasi operasional TI terkait keamanan sistem untuk mendukung layanan TI. 
6. Mengelola Sumber Daya Manusia (APO07)

a. Membuat perencanaan mengenai pengembangan skill apa saja yang perlu dimiliki oleh masing-masing staf, baik yang bersifat teknis maupun yang bersifat non-teknis.

b. Melakukan analisa saat kekurangan SDM yang dibutuhkan, untuk menjalankan kegiatan operasional UNG dalam pengembangan TI serta memberikan pelatihan tentang standar pengelolaan TI seperti COBIT, dan lainnya.

\section{KESIMPULAN}

Evaluasi terhadap tata kelola TI di UNG telah berhasil mengukur tingkat kematangan tata kelola TI pada saat ini, yakni berada pada level Enablished Process yang berarti masih di bawah tingkat kematangan yang diharapkan. Kesenjangan yang terjadi terletak pada kemampuan pihak manajemen kampus dalam mengelola SDM dan strategi TI. Rekomendasi yang diberikan adalah pengetahuan dan keterampilan personel dan pengguna aplikasi TI perlu terus ditingkatkan melalui training yang terjadwal secara rutin. Selain itu, komitmen pihak manajemen UNG terhadap penggunaan TI perlu ditingkatkan agar lebih peduli dalam pemanfaatan TI di lingkungan kampus UNG.

\section{REFERENSI}

Amali, L. N., Mahmuddin, M., \& Ahmad, M. (2014). Information Technology Governance Framework in the Public Sector Organizations. Telkomnika, 12(2), 429-436, http://dx.doi.org/10.12928/telkomnika.v12i2

Amali, L. N. \& Katili, M. R. (2018). Identification of Influential Factors in Implementing IT Governance: A Survey Study of Indonesian Companies in the Public Sector. Interdisciplinary Journal of Information Knowledge, and Management (IJKM), 13, 61-77, https://doi.org/10.28945/3975.

Creswell, J. W. (2009). Research Design: Qualitative, Quantitative, and Mixed Methods Approaches (3rd ed.). California USA: Sage Publications.

Cono, V. A. (2019). Penilaian Tingkat Kapabilitas Proses Tata Kelola Teknologi Informasi Berdasarkan Framework COBIT 5 Pada Domain APO. Skripsi. Universitas Negeri Gorontalo.

Fu, Z. \& Mittnight, E. H. (2015). Critical Success Factors for Continually Monitoring, Evaluating, and Assessing Management of Enterprise IT. Retrieved from http://www.isaca.org/COBIT/focus/Pages/critical-success-factors-for-continuallymonitoring-evaluating-and-assessing-management-of-enterprise-it.aspx

ISACA. (2009). The Risk IT Framework. Retrieved from http://m.isaca.org/COBIT/Documents/ Risk-IT-Framework_fmk_Eng_0610.pdf

ISACA. (2012a). COBIT 5: A Business Framework for the Governance and Management of Enterprise IT. USA: ISACA.

ISACA. (2012b). Cobit Process Assesment Model (PAM): using COBIT 5. USA: ISACA.

Oey-Gardiner, M. (2017). Tantangan Pendidikan Tinggi Indonesia di Era Disrupsi dan Globalisasi. Retrieved from http://sdgcenter.unpad.ac.id/wp-content/uploads/2018/09/ Mayling-Oey-Gardiner-Tantangan-Pendidikan-Tinggi-Indonesia-di-Era-Disrupsi-danGlobalisasi.pdf

Surawan, R. I. (2019). Evaluasi Tata Kelola Teknologi Informasi Menggunakan COBIT 5 Pada Universitas Negeri Gorontalo. Skripsi. Universitas Negeri Gorontalo.

Surendo, K. (2009). Implementasi Tata Kelola Teknologi Informasi. Bandung: Informatika.

Tim TIK UNG. (2016). Blueprint ICT UNG. Gorontalo: Universitas Negeri Gorontalo. 
Van Grembergen, W. \& De Haes, S. (2007). Implementing Information Technology Governance: Models, Practices and Cases. USA: IGI Publishing Hershey, PA

Weill, P., \& Ross, J. W. (2004). IT Governance, How Top Performers Manage IT Decision Rights for Superior Results. Boston: Harvard Business School Press. 